\title{
Determination and occurrence of secondary alkane sulfonates (SAS) in aquatic environments
}

\author{
Rosa María Baena-Nogueras, Eduardo González-Mazo, Pablo A. Lara-Martín* \\ Departamento de Química-Física, Facultad de Ciencias del Mar y Ambientales, Universidad de Cádiz, Campus de Excelencia Internacional del Mar (CEI·MAR), \\ Campus de Río San Pedro s/n, 11510 Puerto Real, Cádiz, Spain
}

\section{A R T I C L E I N F O}

\section{Article history:}

Received 28 September 2012

Received in revised form

10 January 2013

Accepted 15 January 2013

\section{Keywords:}

Surfactants

Wastewater

Sludge

Surface water

Sediment

Estuaries

\begin{abstract}
A B S T R A C T
A new methodology has been developed for the determination of secondary alkane sulfonates (SAS), an anionic surfactant, in environmental matrices. Sediment and sludge samples were extracted using pressurized liquid extraction and sonication, whereas wastewater and surface water samples were processed using solid-phase extraction. Extraction recoveries were acceptable for both aqueous (78-120\%) and solid samples (83-100\%). Determination of SAS was carried out by high or ultra performance liquid chromatography - mass spectrometry using ion trap and time-of-flight detectors. The methodology was applied to samples from Guadalete River (SW Spain), where SAS concentrations below $1 \mu \mathrm{g} \mathrm{L}^{-1}$ were measured in surface water, and from 72 to $9737 \mu \mathrm{g} \mathrm{kg}^{-1}$ in sediments. Differential partitioning was observed for SAS homologues as those having a longer hydrocarbon chain which preferentially sorbed onto particulate matter. A preliminary environmental risk assessment also showed that SAS measured levels were not harmful to the aquatic community in the sampling area.
\end{abstract}

(c) 2013 Elsevier Ltd. All rights reserved.

\section{Introduction}

Many aquatic ecosystems may be jeopardized because of the presence of diverse organic contaminants originating from human activities. In order to minimize negative effects from these chemicals, sewage from most European cities is treated nowadays in wastewater treatment plants (WWTPs) prior to being discharged. Among the different contaminants in wastewater, surfactants are the xenobiotic organic chemicals showing the highest concentrations as a consequence of their huge worldwide production ( $>10$ million tons per year according to Holmberg et al., 2003); with approximately $60 \%$ of this amount belonging to surfactants of the anionic type (Salager, 2002). We have focused our attention in secondary alkane sulfonates (SAS), one of the major anionic surfactants used in dishwashing, laundry and cleaning products (66 000 tons/year in Europe) (HERA Project, 2005). SAS molecular structure consists of a sulfonate group bonded to a linear alkyl chain (linearity $>98 \%$ ) having typically from 14 to 17 carbon units, with an average of 15.9 carbon atoms and an average molecular weight of $328 \mathrm{Da}$. As with many other surfactants, removal of SAS in WWTPs is often about 95-99\% and, according to Field et al. (1995), most of the compound is aerobically degraded in the activated

\footnotetext{
* Corresponding author.

E-mail address: pablo.lara@uca.es (P.A. Lara-Martín).
}

sludge unit (84\%), whereas approximately $16 \%$ of SAS is transferred to the sludge. Measured influent concentrations are between 598 and $976 \mu \mathrm{g} \mathrm{L}^{-1}$, decreasing toward $3-14 \mu \mathrm{g} \mathrm{L}^{-1}$ in the effluent. Highest concentrations ( $509 \mu \mathrm{g} \mathrm{kg}^{-1}$ ) have been reported to occur in sludges (Field et al., 1994), where this surfactant appears to remain stable even after anaerobic digestion (removal was only between 5 and 13\% after 14 days according to Bruno et al., 2002).

In spite of the efficiency of WWTP removing surfactants from wastewater, significant concentrations of these compounds can be measured in many surface water, sediment and suspended solid samples (Prats et al., 1997; Di Corcia, 1998; Matthijs et al., 1999; Morrall et al., 2006). So far, most of the effort has been put into understanding the distribution and environmental behavior of two surfactants: linear alkylbenzene sulfonates (LAS) and nonylphenol polyethoxylates (NPEO). Under our knowledge, there are no available studies on this topic for SAS, excepting a concentration value of $3 \mu \mathrm{g} \mathrm{L}^{-1}$ that was reported in surface waters from Ruhr River (Germany) (Schröeder, 1995). Therefore, there it is necessary to improve the understanding of the environmental behavior of this surfactant. In this sense, the first step would be developing a reliable analytical method for their determination in environmental matrices at trace levels. Few protocols are available for the isolation and analysis of SAS, and most of them are focused on processing samples from WWTPs. Wastewater samples were extracted by solid phase extraction (SPE) using C18 Empore disks (Field et al., 1992a, 1994, 1995), whereas sewage sludge samples 
were processed using ion-pair/supercritical fluid extraction and conventional liquid solvent extraction (Field et al., 1992b). Bruno et al. (2002) employed a homemade apparatus using pressurized solvents instead. Subsequent separation and quantification of SAS homologues has been carried out by high-resolution liquid chromatography with fluorescence detection (HPLC-FL) (Field et al., 1992a) or coupled to mass spectrometry for the simultaneous analysis of these and other surfactants (Bruno et al., 2002). Derivatization of SAS and later analytes by gas chromatography-mass spectrometry (GC-MS) was also accomplished (Field et al., 1992b, 1994, 1995).

The main objectives of this study are: a) to develop a methodology for the analysis of SAS in surface water and sediment samples at sub-ppb levels, and b) to report for the first time the occurrence and distribution of SAS homologues in estuarine settings.

\section{Experimental section}

\subsection{Material and standards}

Formaldehyde, methanol (MeOH), dichloromethane (DCM), acetone (Ac) and ethyl acetate (EA) were of chromatography quality and purchased from Scharlau (Barcelona, Spain), phosphoric acid and sodium sulfate were purchased from Panreac (Barcelona, Spain), and water was Milli-Q quality. The solid-phase extraction (SPE) mini-columns used $\left(500 \mathrm{mg}\right.$ ) were supplied by Varian (Bond Elut $\mathrm{C}_{18}$ ) and by Waters (Oasis HLB). The pure SAS internal standard $\left(C_{12} S A S\right)$, the surrogate $\left(C_{10}\right.$ SAS), and the commercial SAS mixture was supplied by Clariant Produkte, with the following homologue distribution for the commercial mixture: $C_{14}(31 \%), C_{15}(32 \%)$, $\mathrm{C}_{16}(23 \%)$ and $\mathrm{C}_{17}(14 \%)$

\subsection{Sampling and pretreatment}

Wastewater samples and sludge were taken from a WWTP at Puerto Real (SW Spain), a 40000 inhabitant town $\left(36^{\circ} 31^{\prime} 29.88^{\prime \prime} \mathrm{N}, 6^{\circ} 14^{\prime} 07.97^{\prime \prime} \mathrm{O}\right)$. This WWTP treats an average flow of $8000 \mathrm{~m}^{3} \mathrm{~d}^{-1}$ using primary and biologic treatments, and discharges directly into Bay of Cadiz. Additionally, surface water and sediment samples were collected from Guadalete River, within the same area. This river is $157 \mathrm{~km}$ long and flows across the province of Cadiz, entering the sea in the northern part of the Bay of Cadiz. Most of the terrain adjacent to the river is used to irrigate crops, and there are also direct discharges from farms and individual households. Two main pollution sources have been identified in the last stage of the river (Lara-Martín et al., 2008; Corada-Fernandez et al., 2011): a) occasional wastewater discharges from El Puerto de Santa María (80 000 inhabitants), and b) the discharge outlet of a WWTP that serves a town of 200000 inhabitants (Jerez de la Frontera) located upstream. Surface water samples were collected from this river during a tidal cycle at station G0, using amber glass bottles (Fig. 1). Target compounds were preserved by adding $4 \%$ of formaldehyde and keeping the temperature below $4{ }^{\circ} \mathrm{C}$ during their transport to the laboratory, where samples were processed immediately. Solid samples were obtained at five different points (G1-G5) by taking the surface layer $(1-3 \mathrm{~cm}$ ) of sediments by means of PVC cores (length $=60 \mathrm{~cm}$, diameter $=6 \mathrm{~cm}$ ).
Later, sediments were dried in a heater at $65^{\circ} \mathrm{C}$ until constant weight and milled and strained through a $63 \mu \mathrm{m}$ sieve.

\subsection{Solid phase extraction}

First, $200 \mathrm{~mL}$ surface water aliquots $(100 \mathrm{~mL}$ for wastewater) were spiked to $50 \mu \mathrm{g} \mathrm{L}^{-1}$ using $\mathrm{C}_{10}$ SAS as surrogate. Then, these samples (as well as sediment extracts previously redissolved in water) were purified and preconcentrated by $C_{18}$ solid-phase extraction (SPE) mini-columns in an automated SPE Autotrace unit (Zymark). The mini-columns were rinsed with $8 \mathrm{~mL}$ of methanol and $5 \mathrm{~mL}$ of water before passing the aqueous samples at a flow of $3 \mathrm{~mL} \mathrm{~min}^{-1}$. They were then washed with $20 \mathrm{~mL}$ of water, dried, and eluted with $10 \mathrm{~mL}$ dichloromethane/methanol 1:1. The eluate was finally evaporated to dryness and redissolved in $1 \mathrm{~mL}$ of methanol. This protocol was developed by spiking Milli-Q water to $100 \mu \mathrm{g} \mathrm{L}^{-1}$ of a SAS commercial mixture and carrying out several recovery assays for optimizing cartridge type, $\mathrm{pH}$ and extraction solvent.

\subsection{Ultrasonic extraction and pressurized liquid extraction}

Solid samples (sludge and sediment) were extracted using two different techniques: sonication and pressurized liquid extraction (PLE). First, dried and sieved sludge ( $2 \mathrm{~g}$ ) and sediment $(4 \mathrm{~g})$ samples were spiked to $1 \mathrm{mg} \mathrm{kg}^{-1}$ using $\mathrm{C}_{10}$ SAS. These amounts were placed inside PLE stainless steel extraction cells $(22 \mathrm{~mL})$ and mixed with $20 \mathrm{~g}$ of sodium sulfate. Dichloromethane/methanol 1:1 was passed through the heated $\left(100^{\circ} \mathrm{C}\right)$ and pressurized $(1500 \mathrm{psi})$ cells during three cycles of 5 min each using a Dionex ASE 200 unit. Solid samples were also extracted using an ultrasonic bath (Selecta Ultrasons HD $10 \mathrm{~L}$ ). Glass tubes were filled with $0.5 \mathrm{~mL}$ of sample and $10 \mathrm{~mL}$ of dichloromethane/methanol $1: 1$ at $30^{\circ} \mathrm{C}$, extracting SAS homologues during 3 cycles of 30 min each. Solvent was separated from the solid phase by centrifugation during $10 \mathrm{~min}$ at $3500 \mathrm{~g}$ after the end of each cycle, being replaced before starting a new extraction cycle. In both cases, extracts were evaporated to dryness and redissolved in $5 \mathrm{~mL}$ of methanol and $95 \mathrm{~mL}$ of Milli-Q prior purification and preconcentration by SPE. These protocols were developed by spiking non polluted sediment between 2 and $50 \mathrm{mg} \mathrm{kg}^{-1}$ of SAS and carrying out several recovery assays for optimizing the extraction solvent.

\subsection{Liquid chromatography - mass spectrometry}

Analysis of SAS was carried out using two different LC-MS systems. First, $100 \mu \mathrm{L}$ of sample (dissolved in methanol) were mixed with $100 \mu \mathrm{L}$ of water in $2 \mathrm{~mL}$ amber glass vials, and $\mathrm{C}_{12}$ SAS was added as internal standard at a concentration of $1 \mathrm{mg} \mathrm{L}^{-1}$. Then, samples were analyzed using high-performance liquid chromatography coupled to ion trap mass spectrometry (HPLC-IT-MS) (LCQ Thermo Fisher Scientific, Waltham, MA, USA). The injection volume was set to $20 \mu \mathrm{l}$. The chromatographic separation was performed on a reverse-phase C18 analytical column (LiChrospher $100 \mathrm{RP}-18$, Merck) of $250 \mathrm{~mm} \times 2 \mathrm{~mm}$ and $3 \mu \mathrm{m}$ particle size, using methanol and water as solvent at a flow rate of $0.15 \mathrm{~mL} \mathrm{~min}^{-1}$. The elution gradient started at $45 \%$ of methanol and $55 \%$ of water. The percentage of methanol was increased linearly to $100 \%$ during the first $10 \mathrm{~min}$, and kept at $100 \%$ over another $10 \mathrm{~min}$. Total run time was $27 \mathrm{~min}$ including a re-equilibration time of $7 \mathrm{~min}$. The determination of the analytes was carried out using an electrospray source operating in negative ionization mode (ESI-) due to the presence of a sulfonate group in the SAS structure. The source temperature was $220^{\circ} \mathrm{C}$ and the source gas flow was

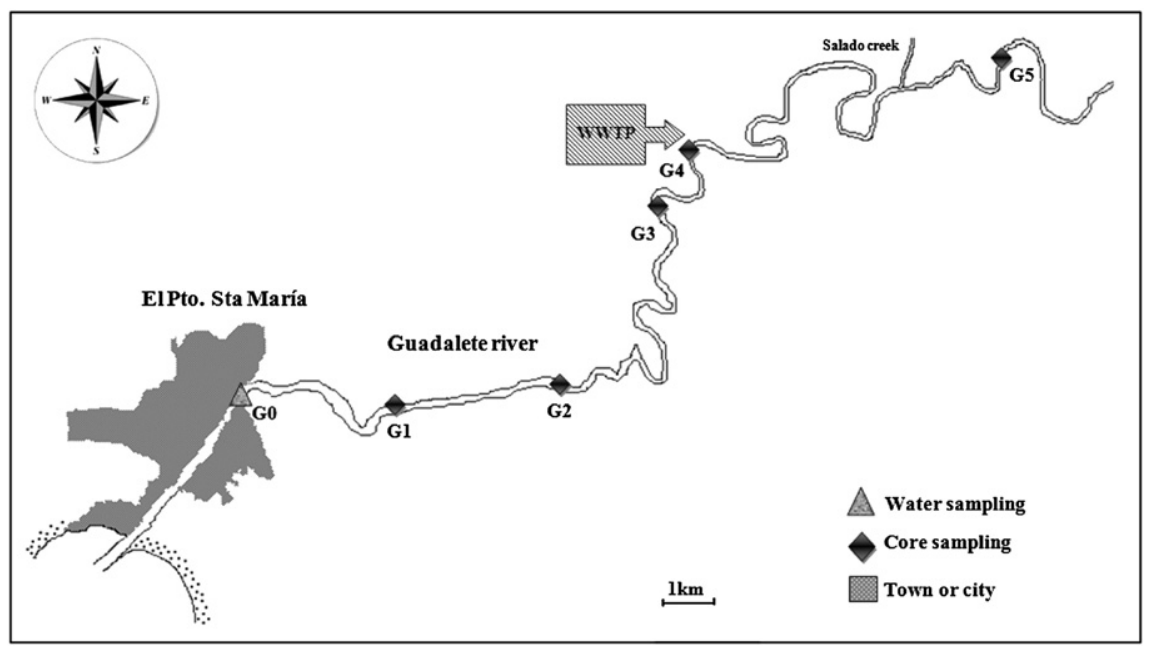

Fig. 1. Map showing the location of the sampling stations (G0-G5) along Guadalete River. 
$60 \mathrm{~mL} \mathrm{~min}^{-1}$. Trap collision energy was established to $35 \mathrm{~V}$. Full-scan mode was selected, measuring the mass/charge ratios $(\mathrm{m} / \mathrm{z})$ between 80 and 600 . Identification of SAS homologues was based on the retention time compared to standards and on the monitoring of their quasimolecular ions $[\mathrm{M}-\mathrm{H}]^{-} \mathrm{m} / \mathrm{z} 277, \mathrm{~m} / \mathrm{z} 291, \mathrm{~m} / \mathrm{z} 305$ and $m / z 319$ for $C_{14}, C_{15}, C_{16}$ and $C_{17} S A S$, respectively.

Additionally, samples were re-analyzed by ultra-performance liquid chromatography coupled to quadrupole-time-of-flight mass spectrometry (Q-ToF-MS) (Synapt G2, Waters Corp., Milford, MA, USA). The injection volume was set to $10 \mu \mathrm{l}$. The chromatographic separation was performed on a reverse-phase C18 analytical column (Acquity UPLC BEH C18, Waters) of $2.1 \mathrm{~mm} \times 50 \mathrm{~mm}$ and $1.7 \mu \mathrm{m}$ particle size using methanol and water as mobile phases at a flow rate of $0.5 \mathrm{~mL} \mathrm{~min}{ }^{-1}$. The elution gradient started at $70 \%$ of methanol and $30 \%$ of water. The percentage of methanol was increased linearly to $95 \%$ during the first $3 \mathrm{~min}$, and then up to $100 \%$ over another $4 \mathrm{~min}$. Total run time was $11 \mathrm{~min}$, including $4 \mathrm{~min}$ for re-equilibration. The determination of the analytes was carried out using an electrospray source operating in negative ionization mode under the following conditions: desolvation gas flow $=600 \mathrm{~L} \mathrm{~h}^{-1}$, desolvation temperature $=350{ }^{\circ} \mathrm{C}$, cone gas flow $=10 \mathrm{~L} \mathrm{~h}^{-1}$, source temperature $=150^{\circ} \mathrm{C}$, capillary voltage $=3000 \mathrm{~V}$, cone voltage $=40 \mathrm{~V}$ and collision energy $=28 \mathrm{eV}$. Full-scan mode was used $(\mathrm{m} / \mathrm{z}=90-400)$. Identification of analytes was achieved by comparing their retention time with those for standards, and by accurate mass measurement (error $<5 \mathrm{ppm}$ ) of the quasimolecular ions $[\mathrm{M}-\mathrm{H}]^{-} \mathrm{m} / \mathrm{z}$ 277.1837, $\mathrm{m} / \mathrm{z} 291.1994, \mathrm{~m} / \mathrm{z} 305.2150$ and $\mathrm{m} / \mathrm{z} 319.2307$ for $\mathrm{C}_{14}, \mathrm{C}_{15}, \mathrm{C}_{16}$ and $\mathrm{C}_{17}$ SAS respectively.

Quantification of analytes was performed using an external calibration curve with concentrations ranging from 10 to $1000 \mu \mathrm{g} \mathrm{L}^{-1}$ for both solid and aqueous samples. The effect of matrix suppression was determined by measuring and comparing the signal intensity of the internal standard in environmental samples and pure solutions (methanol/water 1:1). The precision of the method was calculated as the relative standard deviation (RSD) of replicate measurement. In this sense, sediment, surface water, wastewater and sludge samples were analyzed in duplicate. Furthermore, we also performed three successive injections of the same sample and re-analyzed a batch of samples one month after their first analysis. Limits of detection (LOD) were determined from spiked water and sediment samples as the minimum detectable amount of analyte with a signal to noise ratio of 3 .

\section{Results}

\subsection{Isolation of SAS from aqueous matrices}

Several experiments were performed to optimize solid phase extraction (SPE) of SAS from aqueous samples. First, two types of mini-columns (HLB and $\mathrm{C}_{18}$ ) were selected. Fig. $2 \mathrm{a}$ and $\mathrm{b}$ shows the extraction recovery percentages employing both sorbents and using methanol as elution solvent. It can be observed that SAS extraction efficiencies are similar, ranging between 41 and $66 \%$ for $\mathrm{C}_{18}$ and 42 and $68 \%$ for HLB. This kind of comparison has been previously carried out with other surfactants such as polyethoxylated alcohols (AEO), obtaining recovery percentages in the

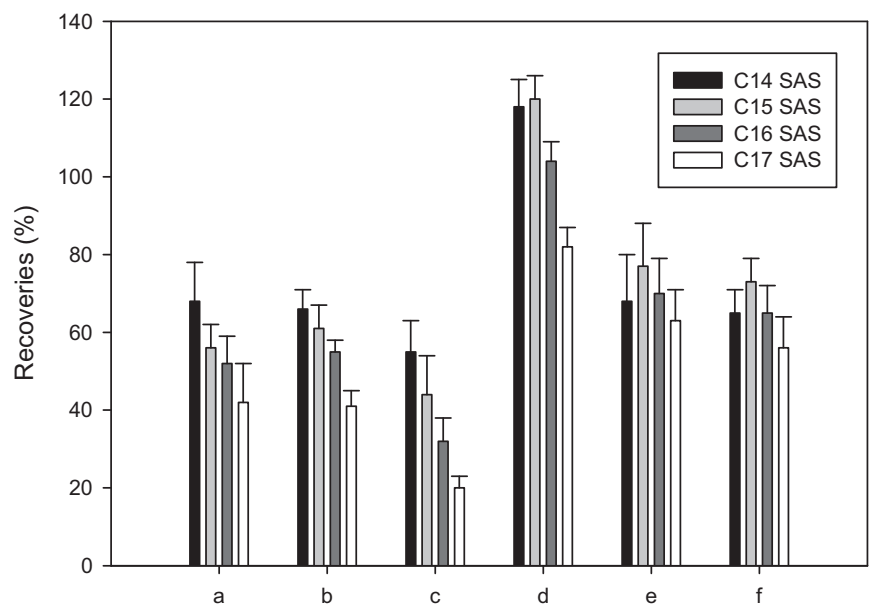

Fig. 2. Extraction recovery percentages for SAS homologues after SPE using (a) HLB and (b) $\mathrm{C}_{18}$ minicolumns at $\mathrm{pH}=7$ and methanol as elution solvent, (c) $\mathrm{C}_{18}$ minicolumns, $\mathrm{pH}=2$ and methanol as elution solvent, and $\mathrm{C}_{18}$ minicolumns, $\mathrm{pH}=7$ and (d) $\mathrm{DCM} / \mathrm{MeOH} 1: 1$, (e) $5 \mathrm{~mL}$ of DCM followed by $5 \mathrm{~mL}$ of $\mathrm{MeOH}$, or (f) $5 \mathrm{~mL}$ of $\mathrm{MeOH} / \mathrm{Ac}$ $1: 1$ followed by $5 \mathrm{~mL}$ of DCM/EA 1:1 as elution solvents. range of $32-76 \%$ when using HLB, and slightly lower values (35$55 \%$ ) for $C_{18}$ (Lara-Martín et al., 2011). In our case, we decided to employ $\mathrm{C}_{18}$ mini-columns for further experiments considering that their extraction efficiencies are comparable for SAS, and also due to the lower cost compared to that for HLB. Thus, the next step was improving the extraction recoveries. We worked with two hypotheses to explain relatively low values obtained during the first experiment (Fig. 2b). The first hypothesis is that the interaction between SAS homologues and the solid phase was not enough so sorption of the analytes was poor. This may happen with many ionic compounds, such as sulfophenyl carboxylic acids (SPC) (LAS metabolites), and can be avoided by changing the $\mathrm{pH}$ of the sample so protonation of the analyte occurs and retention in the minicolumn is enhanced. Thus, previous works have shown that better recoveries were obtained (up to 65\% higher) by acidifying samples for analysis of SPCs and other substances (Lara-Martín et al., 2006a). Fig. 2b and c shows the extraction recovery percentages for SAS at neutral and acidic pH values. Results were similar, although there was a slight decrease in the extraction efficiency when samples were acidified. The same trend was observed for LAS, showing recoveries that are between 3 and 13\% lower for acidified water samples than for those extracted at neutral pH (Lara-Martín et al., 2006a; González-Mazo and Knepper, 2003).

The second hypothesis was that SAS homologues were strongly sorbed onto the solid phase and use of a solvent less polar than methanol would improve the extraction efficiency. Taking into account the results previously obtained (Fig. 2b and c), samples were not acidified this time and several solvent mixtures were tested: a) dichloromethane/methanol 1:1, b) $5 \mathrm{~mL}$ of dichloromethane followed by $5 \mathrm{~mL}$ of methanol, and c) $5 \mathrm{~mL}$ of methanol/acetone 1:1 followed by $5 \mathrm{~mL}$ of dichloromethane/ethyl acetate $1: 1$. Results are shown in Fig. $2 \mathrm{~d}-\mathrm{f}$, and were compared with those obtained using methanol only as extraction solvent (Fig. 2b). Recovery percentages were significantly better ( $>10 \%$ ) when using a mixture of $5 \mathrm{~mL}$ of methanol/acetone $1: 1$ followed by $5 \mathrm{~mL}$ of dichloromethane/ethyl acetate $1: 1$, or $5 \mathrm{~mL}$ of dichloromethane followed by $5 \mathrm{~mL}$ of methanol, instead of just methanol for eluting SAS. These results were within the same range that those obtained for LAS (78-95\%), AEO (67-91\%) and alkyl ethoxysulfates (67-91\%) in a previous study carried out under similar conditions (Lara-Martín et al., 2006a). The best extraction efficiency (close to $100 \%$ for every SAS homologue) was obtained using a mixture of dichloromethane: methanol 1:1 (Fig. 2d). Adding dichloromethane to methanol decreased the polarity of the solvent mixture and enhanced recovery percentages between 32 and $44 \%$ compared to the results obtained when pure methanol is used instead.

\subsection{Extraction of SAS from solid samples}

Ultrasonic extraction was used to extract SAS homologues from sludge and sediment samples. This is a relatively cheap and simple technique that allows processing a large number of samples simultaneously. Three extraction cycles (30 min per cycle, extraction temperature $=30^{\circ} \mathrm{C}$ ) were used according to results on the extraction of LAS, NPEO and AEO from previous studies (LaraMartín et al., 2011, 2012). Three different solvents were used (methanol, dichloromethane and a mixture of methanol/dichloromethane 1:1). Results are shown in Fig. 3. Methanol and the mixture methanol/dichloromethane 1:1 allowed for an efficient extraction of SAS homologues for solid samples, showing recovery percentages between 87 and $97 \%$ and between 83 and 100\%, respectively. In this sense, methanol has proven to be a good choice for the extraction of other anionic and nonionic surfactants (LaraMartín et al., 2011, 2012). A slight decrease in the extraction 


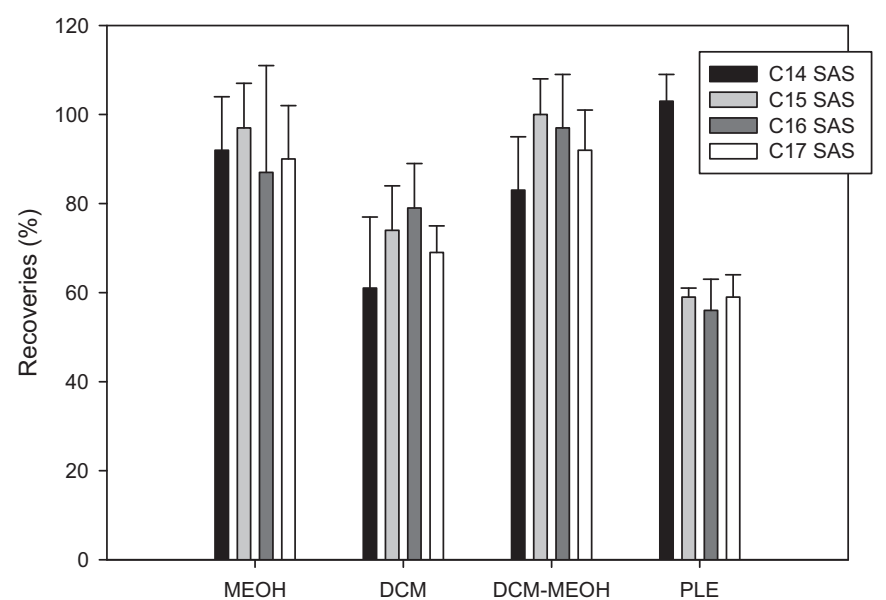

Fig. 3. Extraction recovery percentages for SAS homologues after ultrasonic extraction using $\mathrm{MeOH}, \mathrm{DCM}$ or $\mathrm{DCM} / \mathrm{MeOH} 1: 1$ as extraction solvents. Pressurized liquid extraction (PLE) was also tested using DCM/MeOH 1:1 as extraction solvent.

efficiency was observed when using dichloromethane instead of the other two solvents, which may be due to its lower polarity and, hence, worse interaction with SAS homologues sorpted onto sediments and/or sludges. Finally, dichloromethane/methanol 1:1 was selected as extraction solvent because it was the same mixture used for SPE.

Additionally, ultrasonic extraction was compared with pressurized liquid extraction (PLE), a faster and automated technique previously used by our research group for the extraction of surfactants from sediments. As examples, a mixture of dichloromethane/methanol 3:7 (Lara-Martín et al., 2006a) was proposed for extracting LAS, and methanol was employed in the case of AES (Ding and Fann, 2000; Lara-Martín et al., 2004), showing extraction recovery percentages between 59 and 115\%. In this case, SAS were extracted applying standard conditions ( 3 cycles of 5 min each, pressure $=1500 \mathrm{psi}$, temperature $=100{ }^{\circ} \mathrm{C}$ ) and using the same solvent mixture (dichloromethane/methanol 1:1) that was previously optimized for ultrasonic extraction. Results are shown in Fig. 3. Although the extraction efficiency (106\%) was optimal for $C_{14}$ SAS, more hydrophobic homologues showed recovery percentages below $60 \%$, which are lower than those previously measured for ultrasonic extraction. PLE was not further optimized in this study as ultrasonic extraction proved enough to achieve SAS extraction for solid samples. Better results could be obtained by increasing extraction time or the number of cycles during PLE, as well as by increasing the extraction temperature above $100{ }^{\circ} \mathrm{C}$. Highest temperatures, however, may also enhance the co-extraction of matrix substances, therefore decreasing the ionization of target compounds in electrospray interfaces and raising limits of detection (Petrovic et al., 2002). Overall, using PLE, when available, instead of ultrasonic extraction is justified due to the better reproducibility observed for extraction of SAS homologues (Fig. 3), higher sample capacity ( $4 \mathrm{~g}$ vs $0.5 \mathrm{~g}$ ) and shorter extraction times per sample (20 min vs $2 \mathrm{~h}$ ).

\subsection{Determination of SAS by liquid chromatography-mass spectrometry}

First, separation and determination of SAS homologues was carried out by HPLC-IT-MS. Fig. 4a shows extracted ion chromatograms in negative ion mode. Internal standard ( $C_{12}$ SAS) and surrogate $\left(C_{10} S A S\right)$ are also displayed. SAS homologues were separated according to their affinity for the stationary phase (RP-18), those having a shorter hydrocarbon chain being eluted first. This trend has been previously observed with other anionic surfactants, which are often sold as a mixture of several homologues and isomers, such as LAS or AES (Lara-Martín et al., 2006a,b). SAS isomers depend on the relative position of the sulfonate group to the alkyl chain, and can be classified as external or internal isomers depending on this. There is an existing method that relies on the use of GC-MS for the analysis of SAS in sludge and wastewater samples, allowing the separation not only of SAS homologues but also isomers, although previous derivatization is required (Field et al., 1992b). Conventional HPLC was unsuccessful in separating SAS isomers. In this sense, better results were obtained when re-analyzing samples by UPLC-Q-ToF-MS (Fig. 4b), as UPLC columns use sub $2-\mu \mathrm{m}$ particles that improve the sensitivity and increase the efficiency in the separation. These advantages of using UPLC over HPLC have been recently shown for the environmental analysis of other surfactants, such as NPEO and AEO (Lara-Martín et al., 2012). In this case, partial separation of SAS isomers was achieved and less time per run was required ( $27 \mathrm{~min}$ in HPLC vs $11 \mathrm{~min}$ in UPLC). Internal isomers eluted first than externals as the interaction between the alkyl chain and the stationary phase becomes weaker as the sulfonate group is displaced toward the center of the chain.
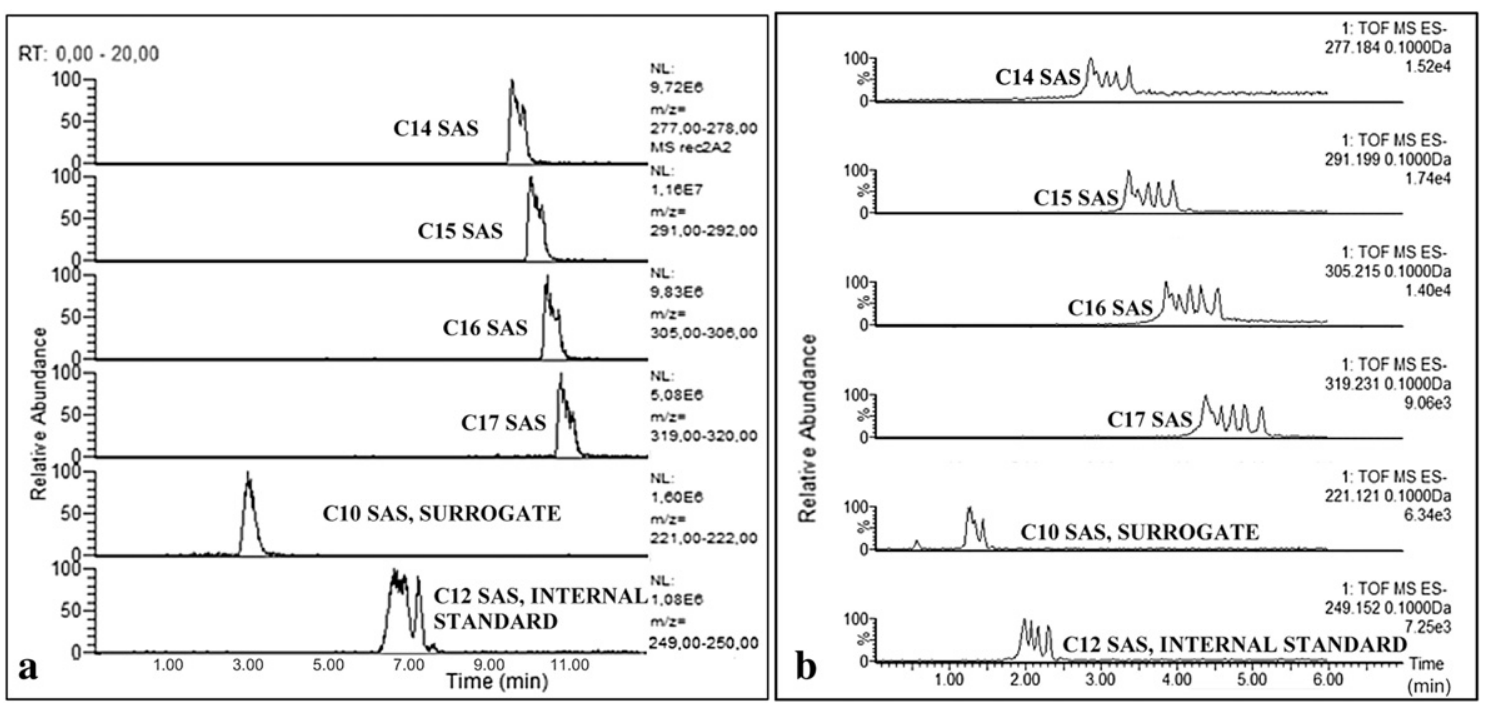

Fig. 4. a) HPLC-IT-MS and b) UPLC-Q-TOF ESI negative ion chromatograms showing the separation of SAS homologues in a standard solution. 
Along with HPLC and UPLC, two different types of mass spectrometers were used for SAS analysis, IT and Q-ToF, respectively. In both cases, SAS homologues were identified by means the mass/ charge ratios of their quasimolecular ions, and capillary and cone voltages were optimized to achieve maximum sensitivity. Mass window was narrowed to $50 \mathrm{mDa}$ for a proper quantification by QToF. Calibration curves from HPLC-IT-MS and UPLC-Q-TOF-MS were obtained for each homologue of SAS, showing an excellent linearity of the curve $\left(r^{2}>0.99\right)$. In the case of IT, the limits of detection (LOD) were from 310 to $650 \mathrm{ng} \mathrm{L}^{-1}$ in water samples, and from 4 to $7 \mu \mathrm{g} \mathrm{kg}^{-1}$ in sediments, depending on the SAS homologue. Instrumental limits of detection were between 7 and $12 \mu \mathrm{g} \mathrm{L}^{-1}$. In the case $\mathrm{Q}-\mathrm{ToF}, \mathrm{LOD}$ ranged from 7 to $22 \mathrm{ng} \mathrm{L}^{-1}$ in water samples, and from 0.5 to $1.1 \mu \mathrm{g} \mathrm{kg}^{-1}$ in sediments, being between 0.7 and $2.1 \mu \mathrm{g} \mathrm{L}^{-1}$ for the instrument. These limits of detection allow the identification of SAS in sewage-polluted environments by HPLC-IT-MS or ULPC-QToF-MS, although the latter is preferred in terms of sensitivity and specificity. Matrix ion suppression was measured using the internal standard ( $\left.\mathrm{C}_{12} \mathrm{SAS}\right)$ added to each sample and was less than $5 \%$ for most samples. SAS concentrations were calculated taking into account not only the response of this internal standard but also that for the surrogate $\left(C_{10} S A S\right)$, which showed a recovery percentage between 70 and $106 \%$, depending on the sample. All samples were analyzed in duplicate; their concentrations showing relative standard deviations (SDs) lower than $20 \%$ in most cases. Resulting SDs were below $10 \%$ for all SAS homologues after carrying out three successive injections of the same sample and re-analyzing a batch of samples one month after their first analysis.

\subsection{Occurrence of SAS in the environment}

Table 1 shows the concentration of SAS homologues in wastewater and sludge from Puerto Real WWTP and in surface water and sediment samples from Guadalete River, both places located within the Bay of Cadiz (SW Spain). SAS has been previously analyzed in raw and treated sewage by Field and coworkers (Field et al., 1994, 1995), showing average concentrations of $946 \mu \mathrm{g} \mathrm{L}^{-1}$ and $3.6 \mu \mathrm{g} \mathrm{L}^{-1}$, respectively, which are comparable with those measured in the present study (472 $\mu \mathrm{g} \mathrm{L}^{-1}$ and $3.8 \mu \mathrm{g} \mathrm{L}^{-1}$ for influent and effluent, respectively). Removal efficiencies were also similar in both cases (>99\%) and within the same range that those reported for other anionic surfactants such as LAS (99.9\%) and AES (98\%) (McAvoy et al., 1998). The removal for each homologue, however, was different, from 63.5 to $93.3 \%$ (Field et al., 1995), and it was due to a combination of degradation in the active sludge unit (84\%) and sorption onto sludge (16\%). In our case, the removal efficiency increased from $96.4 \%$ for $C_{17}$ SAS to $99.5 \%$ for $C_{15}$ SAS (Table 1 ). This differential

Table 1

Concentrations of SAS homologues ( $\mathrm{ppb}$ ) in wastewater (effluent and influent) and sludge from Puerto Real WWTP, and in surface water (range) and sediment samples (G1-G5) from Guadalete River. Removal efficiency (\%) of Puerto Real WWTP is also shown.

\begin{tabular}{lccccc}
\hline & $\mathrm{C}_{14}$ SAS & $\mathrm{C}_{15}$ SAS & \multicolumn{1}{c}{$\mathrm{C}_{16}$ SAS } & \multicolumn{1}{c}{$\mathrm{C}_{17}$ SAS } & Total \\
\hline Effluent & $0.8 \pm 0.2$ & $0.8 \pm 0.2$ & $1.0 \pm 0.3$ & $1.2 \pm 0.3$ & $3.8 \pm 1.0$ \\
Influent & $161 \pm 25$ & $177 \pm 7$ & $100 \pm 4$ & $34 \pm 3$ & $472 \pm 38$ \\
Sludge & $86 \pm 73$ & $564 \pm 9$ & $545 \pm 77$ & $1646 \pm 68$ & $2842 \pm 228$ \\
Removal & 99.5 & 99.5 & 99.0 & 96.4 & 99.2 \\
Surface & $0.02-0.49$ & $0.05-0.29$ & $0.04-0.28$ & $0.04-0.15$ & $0.16-0.99$ \\
$\quad$ water & & & & & \\
G1 & $15 \pm 7$ & $14 \pm 2$ & $18 \pm 10$ & $25 \pm 9$ & $72 \pm 28$ \\
G2 & $30 \pm 7$ & $45 \pm 6$ & $46 \pm 6$ & $83 \pm 22$ & $205 \pm 40$ \\
G3 & $27 \pm 23$ & $55 \pm 19$ & $61 \pm 24$ & $106 \pm 48$ & $250 \pm 114$ \\
G4 & $69 \pm 21$ & $133 \pm 26$ & $85 \pm 11$ & $151 \pm 19$ & $438 \pm 77$ \\
G5 & $374 \pm 66$ & $1822 \pm 348$ & $2895 \pm 616$ & $4646 \pm 928$ & $9737 \pm 1958$ \\
\hline
\end{tabular}

behavior was also reflected in the changes in the homologue composition between different types of samples (Fig. 5). Thus, the homologue distribution for SAS in the influent was very similar to that for commercial standards, although slightly enriched in short-chain homologues (e.g., $6 \%$ higher for $\mathrm{C}_{15}$ SAS) as a consequence of their greater solubility. By contrast, long-chain homologues $\left(\mathrm{C}_{16}\right.$ and $\mathrm{C}_{17}$ SAS) represented the major fraction in samples from the effluent, which may be attributed in part to their lower bioavailability and, hence, slower degradation in the WWTP. The same behavior has been previously observed for LAS homologues in both aerobic and anaerobic degradation assays (León et al., 2006; Lara-Martín et al., 2007). Additionally, long-chain homologues showed a higher tendency to be sorpted onto sludge, where the highest SAS concentrations were measured in this and a previous study by Field et al. (1995) (509 $\mu \mathrm{g} \mathrm{kg}^{-1}$ and $2842 \mu \mathrm{g} \mathrm{kg}^{-1}$, respectively). Thus, the relative amount of $\mathrm{C}_{17} \mathrm{SAS}$ in sludge can be up three times higher than that for commercial standards because of its enhanced hydrophobicity and sorption compared with short-chain homologues (Fig. 5). According to prior studies (Prats et al., 1997; Bruno et al., 2002), concentration of SAS and other anionic surfactants such as LAS in sludges remain stable even after anaerobic digestion.

Fig. 6 shows changes in SAS concentration in surface water during a tidal cycle (from 7:30 h to $18: 30 \mathrm{~h}$ ) at the estuary of Guadalete River (station G0, Fig. 1). SAS levels were between 160 and $990 \mathrm{ng} \mathrm{L}^{-1}$. The only available datum for a comparison is one single measurement ( $3 \mu \mathrm{g} \mathrm{L}^{-1}$ ) at Ruhr River (Germany) (Schröeder, 1995). Concentration of other anionic surfactants was previously determined in surface waters from Guadalete River. AES levels were within the same range as SAS values reported here, whereas average LAS concentrations were significantly higher $\left(40 \mu \mathrm{g} \mathrm{L}^{-1}\right)$ (LaraMartín et al., 2008) due to the more widespread use and higher consumption volume of this surfactant in the market. With respect to the variations of SAS concentrations during the tidal cycle, the lowest values were found during the first $5 \mathrm{~h}$ (flooding), from 160 to $460 \mathrm{ng} \mathrm{L}^{-1}$ (average SAS concentration $=280 \mathrm{ng} \mathrm{L}^{-1}$ ). The minimum value was found when the tide was high and may be explained by an input of relatively clean water from the ocean. Consistent with this interpretation, SAS concentration sharply increased due to the increase in the relative contribution of water from upstream, where the main pollution sources are located (e.g., Jerez de la Frontera WWTP outlet). The maximum value was found at 17:30 $\mathrm{h}\left(991 \mathrm{ng} \mathrm{L}^{-1}\right)$, when the tide is low. The average distribution of SAS homologues in surface water is shown in Fig. 5, and it was very similar to that found in samples from the WWTP effluent, suggesting that sewage discharges are the main source of this surfactant in the aquatic environment. This was confirmed later on

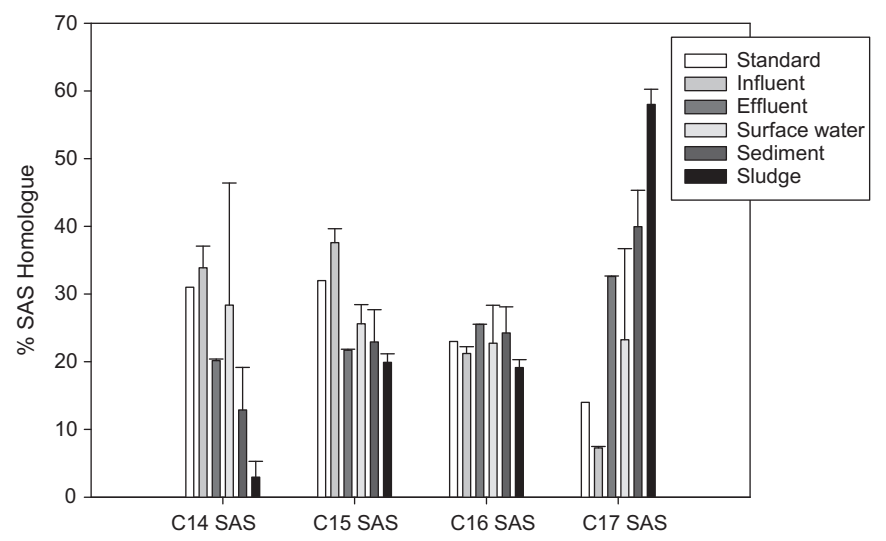

Fig. 5. SAS homologue distributions in a commercial standard and several aqueous and solid environmental matrices. 


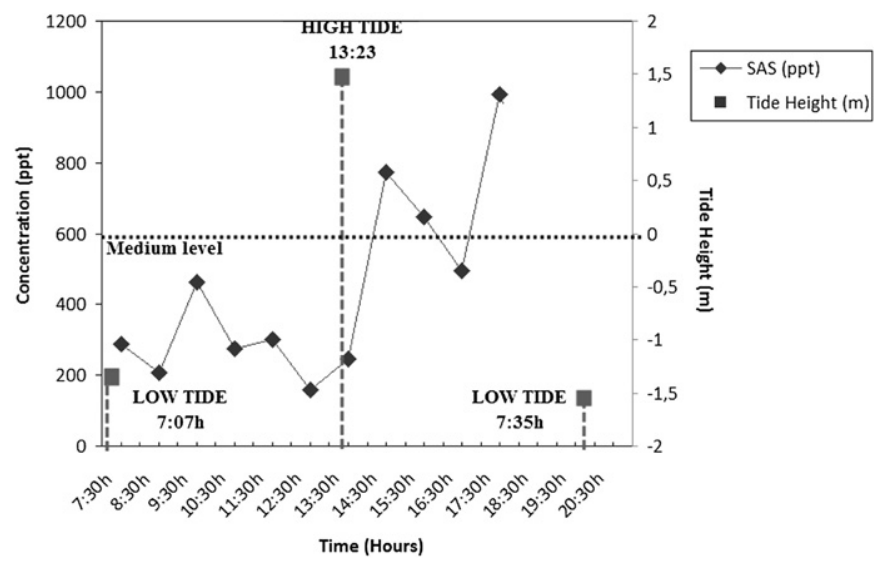

Fig. 6. Evolution in SAS concentration during a tidal cycle at Guadalete River (station G0).

by sampling surface sediments along the Guadalete estuary (stations G1 to G5, Fig. 1). Concentration of SAS in the bottom of the river increased upstream, from G1 toward G5 (Table 1). Previous samplings at this area have reported significantly high values of AES and LAS ( $>1 \mathrm{mg} \mathrm{kg}^{-1}$ and $>10 \mathrm{mg} \mathrm{kg}^{-1}$, respectively) at $\mathrm{G} 4$, which is adjacent to the effluent of Jerez de la Frontera WWTP (Lara-Martín et al., 2008). The highest SAS values ( $9.7 \mathrm{mg} \mathrm{kg}^{-1}$ ), however, were reached at station $G 5$, close to where untreated wastewater is dumped from the WWTP during heavy rainfall episodes. Additionally, sewage is from rural isolated areas not connected to the WWTP is collected at Salado creek and discharged into the river. Station G5 is an exceptionally polluted place where concentrations higher than $200 \mathrm{mg} \mathrm{kg}^{-1}$ have been previously measured for LAS (Corada-Fernandez et al., 2011). Nevertheless, concentrations of anionic surfactants decreased drastically a few meters away in both directions, and, for SAS, were always below $0.5 \mathrm{mg} \mathrm{kg}^{-1}$ along the rest of the estuary. The distribution of SAS homologues in surface sediments (Fig. 5) was comparable with that observed in sludge samples, being enriched in those homologues with a longer hydrocarbon chain length and higher sorption capacity.

Finally, we conducted a preliminary environmental risk assessment (ERA) for SAS. No data on sediment or soil ecotoxicity were available, so we have focused our study to the water column. In short, ratios of the predicted or already measured environmental concentrations (PECs) and the predicted no-effect concentrations (PNECs) that are below 1 are not considered a risk to organisms. The highest concentrations for SAS in surface water and treated wastewater reported here are $990 \mathrm{ng} \mathrm{L^{-1 }}$ and $3.76 \mu \mathrm{g} \mathrm{L}^{-1}$, respectively. We have selected these values as PECs, representing the worst-case scenario. On the other hand, PNECs for SAS can be calculated in several ways. As examples, PNEC $=37 \mu \mathrm{g} \mathrm{L}^{-1}$ for surface water was calculated from the no observed effect concentration (NOEC) on the reproduction of Daphnia magna, and PNEC $=70 \mathrm{mg} \mathrm{L}^{-1}$ for wastewater was determined from results from a chronic study on the bacterial cell growth (HERA Project, 2005). Additionally, several acute aquatic ecotoxicity assays have been carried out using different species, showing lethal concentration $50 \%$ values (LC50 after $96 \mathrm{~h}$ ) from 1 to $14.8 \mathrm{mg} \mathrm{L}^{-1}$ of SAS, and from 1.3 to $144 \mathrm{mg} \mathrm{L}^{-1}$ for Danio rerio and Lepomis macrochirus, respectively. Half maximal effective concentrations (EC50 after $24 \mathrm{~h}$ ) between 2 and $319 \mathrm{mg} \mathrm{L}^{-1}$ were calculated for the invertebrate Daphnia magna, and between 96 and $311 \mathrm{mg} \mathrm{L}^{-1}$ for the algae Scenedesmus subspicatus. EC10 values up to $1000 \mathrm{mg} \mathrm{L}^{-1}$ were reported for Pseudomonas putida after $16 \mathrm{~h}$ in a chronic toxicity study (HERA Project, 2005). Is expected that PEC/PNEC ratio values for SAS are going to be always below 1 , which means that no damage for aquatic community is predicted considering the SAS concentrations measured in the sampled areas.

\section{Conclusions}

This paper described a new methodology for the analysis of SAS in both aqueous and solid environmental samples and documented the occurrence of this surfactant at the estuary of Guadalete River (SW Spain). Modern analytical techniques such as UPLC proved advantageous over more conventional approaches such as liquid solvent extraction or GC-MS in terms of efficiency, selectivity and reproducibility for SAS analysis. This compound was detected often at ppb (parts per billion) or ppt (parts per trillion) levels in wastewater and surface water, increasing its concentration in sludge and sediment samples due to the affinity of longer alkyl chain homologues for the particulate phase. SAS concentrations were within the same range than those previously found in the same sampling area for AES, another anionic surfactant, and significantly lower than those for the most widely used and better known LAS. Some of these data are among the first ever reported on SAS distribution in an aquatic environment. Further research is recommended for a better understanding on the environmental behavior of this surfactant and for improving the quality of further risk assessments.

\section{Acknowledgments}

We express our gratitude to E. de Miguel for his technical support with the LC-MS systems. We also thank Clariant Produkte (OT 2010/105) for providing funding for this research. Part of this work has been also carried out within two regional research projects (RNM 5417 and RNM 6613) funded by Consejería de Innovación, Ciencia y Empresa (Junta de Andalucía).

\section{References}

Bruno, F., Curini, R., Di Corcia, A., Fochi, I., Nazzari, M., Samperi, R., 2002. Determination of surfactants and some of their metabolites in untreated and anaerobically digested sewage sludge by subcritical water extraction followed by liquid chromatography-mass spectrometry. Environmental Science \& Technology $36,4156-4161$.

Corada-Fernandez, C., Lara-Martín, P.A., Candela, L., González-Mazo, E., 2011. Tracking sewage derived contamination in riverine settings by analysis of synthetic surfactants. Journal of Environmental Monitoring 13, 2010-2017.

Di Corcia, A., 1998. Characterization of surfactant $s$ and their biointermediates by liquid chromatography-mass spectrometry. Journal of Chromatography A 794 165-185.

Ding, W.-H., Fann, J.C.H., 2000. Determination of linear alkylbenzenesulfonates in sediments using pressurized liquid extraction and ion-pair derivatization gas chromatography-mass spectrometry. Analytica Chimica Acta 408, 291-297.

Field, J.A., Leenheer, J.A., Thorn, K.A., Barber II, L.B., Rostad, C., Macalady, D.L. Daniel, S.R., 1992a. Identification of persistent anionic surfactant-derived chemicals in sewage effluent and groundwater. Journal of Contaminant Hydrology 9, 55-78.

Field, J.A., Miller, D.J., Field, T.M., Hawthorne, S.B., Giger, W., 1992b. Quantitative determination of sulfonated aliphatic and aromatic surfactants in sewage sludge by ion-pair/supercritical fluid extraction and derivatization gas chromatography/mass spectrometry. Analytical Chemistry 64, 3161-3167.

Field, J.A., Field, T.M., Poiger, T., Giger, W., 1994. Determination of secondary alkane sulfonates in sewage wastewaters by solid-phase extraction and injection-port derivatization gas chromatography/mass spectrometry. Environmental Science \& Technology 28, 497-503.

Field, J.A., Field, T.M., Poiger, T., Siegrist, H., Giger, W., 1995. Fate of secondary alkane sulfonate surfactants during municipal wastewater treatment. Water Research 29, 1301-1307.

González-Mazo, E., Knepper, T.P., 2003. Sample handling. In: Knepper, T.P. Barceló, D., De Voogt, P. (Eds.), Comprehensive Analytical Chemistry. Elsevier, Amsterdam, pp. 393-441.

HERA Project, 2005. Secondary Alkane Sulfonates (SAS) in Human and Environmental Risk Assessment on Ingredients of Household Cleaning Products, Environmental Risk Assessment Report. Brussels, Belgium.

Holmberg, K., Jönsson, B., Kronberg, B., Lindman, B., 2003. Introduction to surfactants. In: John Wiley \& Sons (Ed.), Surfactants and Polymers in Aqueous Solution. E-Publishing Inc., Chichester, pp. 1-37. 
Lara-Martín, P.A., Gómez-Parra, A., González-Mazo, E., 2004. Pressurized liquid extraction followed by liquid chromatography-mass spectrometry for the determination of major surfactants in marine sediments. International Journal of Environmental and Analytical Chemistry 85 (4-5), 293-303.

Lara-Martín, P.A., Gómez-Parra, A., González-Mazo, E., 2006a. Development of a method for the simultaneous analysis of anionic and non-ionic surfactants and their carboxylated metabolites in environmental samples by mixed-mode liquid chromatography-mass spectrometry. Journal of Chromatography A 1137, 188-197.

Lara-Martín, P.A., Gómez-Parra, A., González-Mazo, E., 2006b. Simultaneous extraction and determination of anionic surfactants in waters and sediments. Journal of Chromatography A 1114, 205-210.

Lara-Martín, P.A., Gómez-Parra, A., Köchling T. Sanz, J.L. González-Mazo, E., 2007. Anaerobic degradation of linear alkylbenzene sulfonates in coastal marine sediments. Environmental Science \& Technology 41, 3573-3579.

Lara-Martín, P.A., Gómez-Parra, A., González-Mazo, E., 2008. Sources, transport an reactivity of anionic and non-ionic surfactants in several aquatic ecosystems in SW Spain: a comparative study. Environmental Pollution 156, 36-45.

Lara-Martín, P.A., González-Mazo, E., Brownawell, B.J., 2011. Multi-residue method for the analysis of synthetic surfactants and their degradation metabolites in aquatic systems by liquid chromatography-time-of-flight-mass spectrometry. Journal of Chromatography A 1218, 4799-4807.

Lara-Martín, P.A. González-Mazo, E. Brownawell, B. J., 2012. Environmental analysis of alcohol ethoxylates and nonylphenol ethoxylate metabolites by ultraperformance liquid chromatography-tandem mass spectrometry. Analytical and Bioanalytical Chemistry 402, 2359-2368.
León, V.M., López, C., Lara-Martín, P.A., Prats, P., Varó, P., González-Mazo, E., 2006. Removal of linear alkylbenzene sulfonates and their degradation intermediates at low temperatures during activated sludge treatment. Chemosphere 64, 1157-1166.

Matthijs, E., Holt, M.S., Kiewiet, A., Rijs, G.B.J., 1999. Environmental monitoring for linear alkylbenzene sulfonate, alcohol ethoxylate, alcohol ethoxy sulfate, alcohol sulfate, and soap. Environmental Toxicology and Chemistry 18, 2634-2644.

McAvoy, D.C., Dyer, S.D., Ferdinger, N.J., Eckhoff, W.S., Lawrence, D.L., Begley, W.M., 1998. Removal of alcohol ethoxylates, alkyl ethoxylate sulfates, and linear alkylbenzene sulfonates in wastewater treatment. Environmental Toxicology and Chemistry 17, 1705-1711.

Morrall, S.W., Dunphy, J.C., Cano, M.L., Evans, A., McAvoy, D.C., Price, B.P., Eckhoff, W.S. 2006. Removal and environmental exposure of alcohol ethoxylates in US sewage treatment. Ecotoxicology and Environmental Safety 64, 3-13.

Petrovic, M., Lacorte, S., Viana, P., Barceló, D., 2002. Pressurized liquid extraction followed by liquid chromatography-mass spectrometry for the determination of alkylphenolic compounds in river sediment. Journal of Chromatography A 959, 15-23.

Prats, D., Ruiz, F., Vázquez, B., Rodríguez-Pastor, M., 1997. Removal of anionic and nonionic surfactants in a wastewater treatment plant with anaerobic digestion. A comparative study. Water Research 31, 1925-1930.

Salager, J.L., 2002. Surfactants: Types and Uses. University of the Andes, Faculty of Engineering, School of Chemical Engineering, FIRP.

Schröeder, F.R., 1995. Concentrations of anionic surfactants in receiving riverine water: results of a long-term monitoring programme in the river Rur. Tenside Surfactants Detergents 32, 492-497. 